\title{
AUTOGENOUS AND ISOTHERMAL RESTRAINED SHRINKAGE OF HYDRATING CEMENT PASTES - EXPERIMENTAL STUDY
}

\author{
Arnaud Pertue, Pierre Mounanga, Abdelhafid Khelidj and Denis Fournol \\ GeM UMR CNRS 6183 - Research Institute on Civil Engineering and Mechanics \\ IUT de Saint-Nazaire, 58, rue Michel Ange, BP 420, F-44606 Saint-Nazaire, France \\ Arnaud.pertue@univ-nantes.fr, Pierre.mounanga@univ-nantes.fr, \\ Abdelhafid.khelidj@univ-nantes.fr, Denis.fournol@univ-nantes.fr
}

Numerous studies have been carried out to characterize the autogenous shrinkage of cement-based materials in free conditions at early and very early age. But the results obtained are not sufficient to understand the autogenous volume variations of concrete in realistic structural conditions. Indeed, the analysis of such deformations requires investigating the cementitious system's behaviour in restrained conditions, when the internal stresses generated can lead to the premature cracking of the material.

This study focuses on the influence of the curing temperature on the early age cracking of cement-based materials in restrained and autogenous conditions. The test method used is the "ring test", largely described in the literature (Grysbowski and Shah [1], Weiss [2] for example). This method was firstly developed to study the cracking of mortars and concretes due to drying. In the present research work, water evaporation is prevented during the whole test duration and each ring test apparatus is equipped with a peripheral water circulation system, which enables to control the temperature of the specimen investigated (Fig. 1).

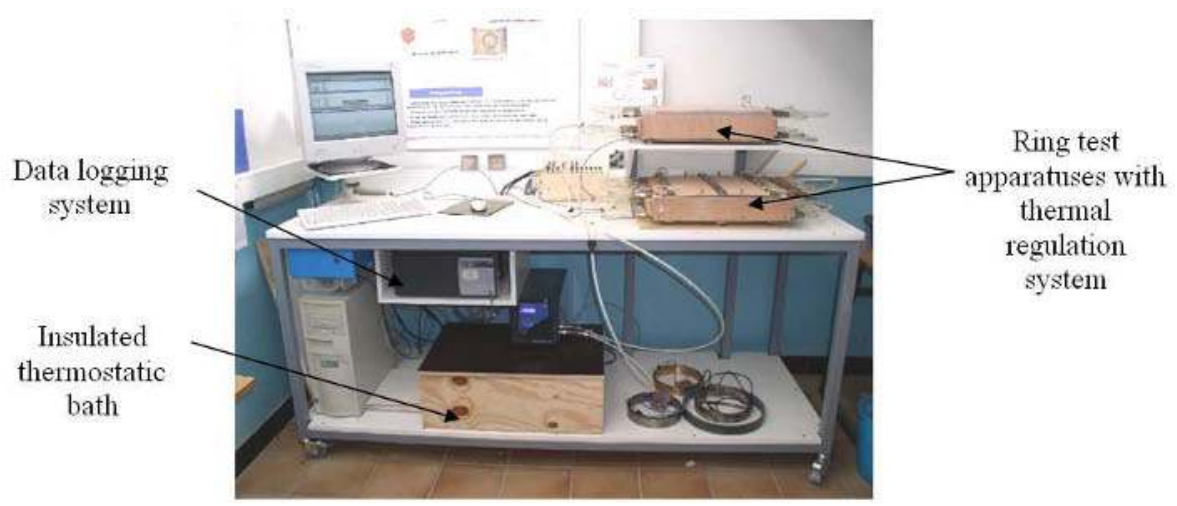

FIGURE 1. General view of the experimental device

The peripheral water circulation is ensured by a network of copper tubes connected to a thermostated bath, which makes it possible to maintain the sample in quasi-isothermal conditions.

The test procedure begins with the casting of the freshly mixed cement-based material around a central metal ring. The deformations of the metal ring due to the cement paste's shrinkage are then measured by strain gauges stuck on the internal annulus surface and are automatically 
recorded by the data logging system. The test stops at the appearance of the first transversal crack, caused by the internal stresses generated by the autogenous shrinkage.

The experimental program of the study consists in applying three different curing temperatures $\left(10 ; 20\right.$ and $\left.40^{\circ} \mathrm{C}\right)$ to cement pastes prepared with three types of cement (CEM I, CEM II and CEM III) and two water-to-cement ratios $(\mathrm{W} / \mathrm{C}=0.3$ and 0.4$)$. Moreover, in order to study the effect of the ring restriction degree, three different metals (steel, brass and stainless steel) are used for the central ring. Then two comparisons are carried out: the evolution of the deformations at various temperatures as a function of time and as function of hydration degree. This latter is obtained using the NIST's program, CEMHYD3D [3].

Numerical simulations are also carried out in order to compare the measured cracking age with the one computed through the model developed by Turcry et al. [4]. These calculations are based on the material characteristics (hydration degree and autogenous shrinkage evolutions) and the ring geometry.

The results obtained show that the curing temperature directly influences the age of the first crack. This phenomenon is linked to the thermoactivation of the hydration process, which causes, according to the temperature applied, an acceleration or a deceleration of the deformations and, consecutively, of the internal stresses. A discussion, taking account of the calculation of the apparent activation energy is undertaken in order to quantify more finely the effect of temperature on the prevented deformation of cement-based materials.

\section{References}

1. Grzybowski, M. and Shah, P., ACI Material Journal, vol. 87, 138-148, 1990.

2. Weiss, W.J., PhD Thesis, Evanston, Illinois, 1999.

3. Bentz, D.P., CEMHYD3D: A Three-Dimensional Cement Hydration and Microstructure Development Modelling Package Version 2.0., 2000.

4. Turcry, P., Loukili, A., Haidar, K., Pijaudier-Cabot, G., Berlarbi, A., J. Mat. in Civ. Engrg., vol. 18 (1), 46-54, 2006. 